\title{
Sobrecarga de trabalho em cuidadores de idosos frágeis: revisão integrativa
}

RESUMO | Objetivo: analisar a sobrecarga de trabalho e suas conseqüências no cuidador de idosos frágeis. Método: trata-se de um estudo descritivo, exploratório, com base em uma revisão integrativa, realizada nas bases de dados online da Biblioteca Virtual de Saúde, sendo elas: LILACS e SCIELO. A amostra do estudo foi constituída por 14 artigos publicados entre 2009 e 2019. Utilizou-se um formulário como instrumento de coleta de dados. Resultados: os estudos enfatizam o ônus biopsicossocial decorrente do desgastante laboral, forjada numa repetitiva rotina diária incessante, muitas vezes durante anos, com sobrecarga de atividade no seu cotidiano, tratando não só de uma sobrecarga nas atividades, mas também de uma ameaça a sua saúde. Conclusão: a assistência do cuidador familiar requer uma atenção especial tendo em vista a prevenção de agravos a sua saúde, sendo que os cuidados com idosos dependentes são desgastantes e implica risco a saúde física e mental do cuidador.

Palavras-chaves: Envelhecimento; Idoso; Cuidadores.

ABSTRACT | Objective: to analyze the work overload and its consequences in the caregiver of fragile elderly. Method: it is a descriptive, exploratory study, based on an integrative review, performed in the online databases of the Virtual Health Library: LILACS and SCIELO. The study sample consisted of 14 articles published between 2009 and 2019. A form was used as a data collection tool. Results: the studies emphasize the biopsychosocial burden of labor fatigue, forged in a repetitive daily routine, often for years, with overload of activity in their daily lives, dealing not only with an overload in activities, but also a threat to their health. Conclusion: the care of the family caregiver requires special attention in order to prevent aggravation to his or her health, and the care of dependent elderly people is stressful and entails risk to the physical and mental health of the caregiver.

Keywords: Aging; Elderly; Caregivers.

RESUMEN | Objetivo: analizar la sobrecarga de trabajo y sus consecuencias en el cuidador de ancianos frágiles. Método: Se trata de un estudio descriptivo y exploratorio, basado en una revisión integradora, realizada en las bases de datos online de la Biblioteca Virtual de Salud: LILACS y SCIELO. La muestra del estudio consistió en 14 artículos publicados entre 2009 y 2019 . Se utilizó un formulario como herramienta de recogida de datos. Resultados: los estudios destacan la carga biopsicosocial de la fatiga laboral, forjada en una rutina diaria repetitiva, a menudo durante años, con sobrecarga de actividad en su vida cotidiana, enfrentándose no sólo a una sobrecarga en las actividades, sino también a una amenaza para su salud. Conclusión: el cuidado del cuidador familiar requiere una atención especial con el fin de prevenir el agravamiento de su salud, y el cuidado de las personas mayores dependientes es estresante y conlleva un riesgo para la salud física y mental del cuidador.

Palabras claves: Envejecimiento; Anciano; Cuidadores.

\section{Patrick Leonardo Nogueira da Silva}

Enfermeiro, Mestrando pelo Programa de Pós-Graduação em Cuidado Primário em Saúde da Universidade Estadual de Montes Claros (PPGCPS/UNIMONTES). Montes Claros, MG, Brasil.

ORCID: 0000-0003-2399-9526

\section{Cláudio Luís de Souza Santos}

Enfermeiro, Especialista em Saúde Mental pela Residência Multiprofissional da Universidade Estadual de Montes Claros (UNIMONTES). Montes Claros, MG, Brasil. ORCID: 0000-0002-9127-6349

\section{Fábio Batista Miranda}

Enfermeiro, Doutorando pelo Programa de Pós-Graduação em Enfermagem e Biociências da Universidade Federal do Estado do Rio de Janeiro (PPGENFBIO/UNIRIO). Rio de Janeiro, RJ, Brasil.

ORCID: 0000-0003-0934-980X

\section{Ana Patrícia Fonseca Coelho Galvão}

Enfermeira, Mestre em Saúde e Ambiente, Professora do Departamento de Enfermagem da Universidade Ceuma (UNICEUMA). São Luís, MA, Brasil.

ORCID: 0000-0003-3376-5678

\section{Valdira Vieira de Oliveira}

Enfermeira, Mestre em Enfermagem, Professora do Departamento de Enfermagem da Faculdade Santo Agostinho (FASA). Montes Claros, MG, Brasil.

ORCID: 0000-0003-2020-2489

\section{Carolina dos Reis Alves}

Enfermeira, Doutora em Ciências da Saúde, Professora do Departamento de Enfermagem da Faculdade Santo Agostinho (FASA). Montes Claros, MG, Brasil.

ORCID: 0000-0003-2107-6306

Recebido em: 07/02/2021

Aprovado em: 26/02/2021
INTRODUÇÃO

o último censo demográfico
realizado no Brasil no ano
de 2012 , estima-se que o número de pessoas com 60 anos ou mais de idade se aproxima de 14,5 milhões, com projeção para cerca de 32 milhões em 2015, o que colocará na sexta posição entre os países com maior proporção de idosos no mundo(1). Segundo o Instituto Brasileiro de Geografia e Estatística (IBGE), o número de idosos no Brasil nos últimos 20 anos dobrou, e até o ano de 2050 alcançará mais de 25\% da população. Segundo a Organização Mundial de Saúde (OMS) (2), no Brasil é considerado idoso a pessoa com 60 anos ou mais. Essa definição foi estabelecida pelo Ministério da Saúde (MS), no Estatuto do Idoso, conforme a Lei $n^{\circ} 10.741$, 
de $1^{\circ}$ de outubro de $2003^{(3)}$. O envelhecimento pode ser entendido como um conjunto de transformações fisiológicas, morfológicas, bioquímicas e psicológicas que determina a diminuição no processo de adaptação do indivíduo ao meio em que vive, sendo considerado um processo gradativo e dinâmico ${ }^{(4)}$.

O envelhecimento também pode ser representado como um processo biopsicosociocultural e, por essa natureza, gera demandas complexas e exige cuidado diferenciado $^{(1)}$. Não significa afirmar que é uma doença, mas uma etapa de vida com características e valores próprios, em que ocorrem modificações no indivíduo, tanto na estrutura orgânica, como no metabolismo, no equilíbrio bioquímico, imunidade, nutrição, nos mecanismos funcionais, nas condições emocionais, intelectuais, e ainda, na própria comunicação. Atualmente observa-se, no mundo todo, o aumento absoluto e proporcional da população idosa e, sabendo-se que o declínio da capacidade funcional aumenta com a idade, todos os esforços devem ser envidados no sentido de prevenir a dependência física e de retardá-la o máximo possível, para que o idoso possa viver por mais tempo no seu ambiente familiar ${ }^{(5)}$.

Sabe-se que, à medida que o ser humano vai envelhecendo, muitas tarefas do cotidiano consideradas banais e, portanto, de fácil execução, vão paulatinamente e imperceptivelmente tornando-se cada vez mais difíceis de serem realizadas, até que o indivíduo percebe que já depende de outra pessoa para a realização das atividades de vida diárias (AVD) ${ }^{(5)}$. Com isso, torna-se evidente a dependência desses idosos sobre os cuidadores. A dependência pode ser considerada, ainda, como um estado em que as pessoas se encontram por razões ligadas à falta ou perda de autonomia (física, psíquica, social), de necessidade de ajuda para realizar as AVD. É um problema grave de saúde que interfere na qualidade de vida (QV) do idoso e do seu cuidador ${ }^{(6)}$.

A proporção de idosos brasileiros com alguma dificuldade para desem- penhar as AVD é de aproximadamente $13,5 \%$, sendo mais frequente em muIheres e em pessoas acima dos oitenta anos. Nesse contexto, a disponibilização do auxílio de outra pessoa ou cuidador para tomar banho, vestir-se, alimentar-se e/ou fazer a própria higiene, por exemplo, torna-se imprescindível ${ }^{(7)}$. Define-se como cuidador a "pessoa que desempenha a função de ajudar pessoas dependentes, numa relação de proximidade física e afetiva ${ }^{(8)}$. Sendo assim, cuidar é mais que um ato, é uma atitude, de modo a abranger mais que um momento de atenção, ou seja, representa uma atitude de ocupação, preocupação, responsabilidade e envolvimento afetivo com o outro ${ }^{(9)}$.

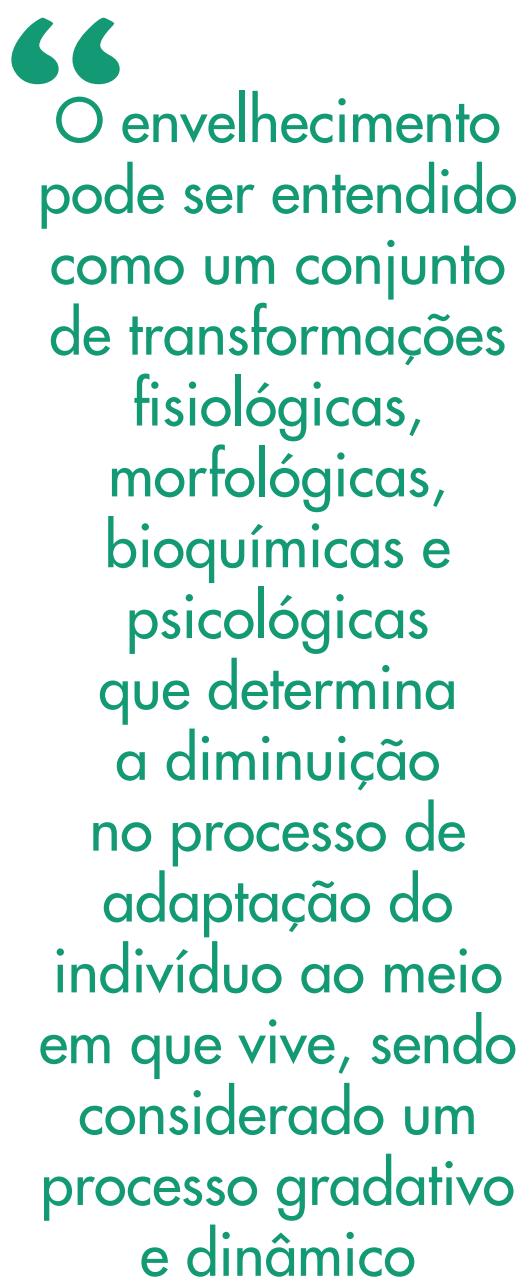

99
A sobrecarga relacionada ao cuidado é um construto complexo, que compreende uma série de aspectos e consequências na vida dos cuidadores e suas famílias e tem sido relacionada ao desenvolvimento de diversos problemas ${ }^{(10,11)}$. Nesse contexto, diante do aumento da população idosa no Brasil e devido às alterações decorrentes do processo de envelhecimento, certamente o idoso dependerá do cuidador familiar para o desenvolvimento das suas AVD. Sendo assim, este estudo objetivou analisar a sobrecarga de trabalho e suas conseqüências no cuidador de idosos frágeis.

\section{MÉTODO}

Trata-se de um estudo descritivo, exploratório, documental, retrospectivo, embasado em uma Revisão Integrativa da Literatura (RIL), a qual tem a finalidade de reunir, avaliar e condensar os resultados de pesquisa sobre um determinado tema de forma sistemática e ordenada, sendo um instrumento que aprofunda o conhecimento do tema investigado permitindo a síntese dos estudos publicados, evidenciando o estado atual do conhecimento assim como as suas falhas ${ }^{(4)}$.

Foi realizada uma busca pelas bases de dados online da Biblioteca Virtual de Saúde, sendo elas: Literatura Latino-Americana e do Caribe em Ciências da Saúde (LILACS) e Scientific Electronic Library Online (SCIELO). Para a localização dos artigos, foram utilizados os seguintes descritores: "envelhecimento", "idoso", e "cuidadores". Ainda, os mesmos foram combinados entre si pelo operador booleano "AND" no intuito de definir relações entre os termos em uma pesquisa, ou seja, os termos são combinados para que cada resultado contenha no mínimo um dos termos.

O estudo obedeceu três etapas, sendo elas: 1) identificaram se os descritores controlados por meio dos Descritores em Ciências da Saúde (DeCS), selecionando aqueles considerados pertinentes para a consecução da pesquisa; 2) realizou-se a 


\section{Figura 1 - Percurso metodológico da captação amostral.}

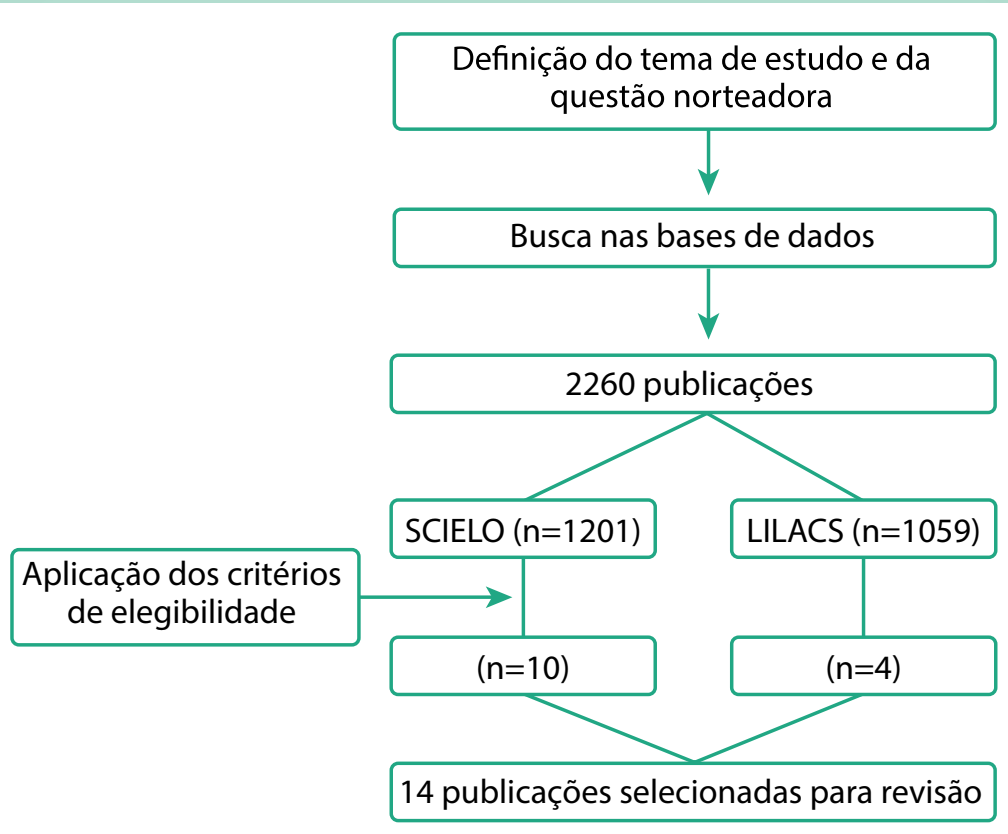

Tabela 1 - Perfil da amostragem do estudo conforme descritores e bases de dados.

\begin{tabular}{lcccccc} 
& \multicolumn{1}{c}{ SCIELO } & \multicolumn{2}{c}{ LILACS } & \multicolumn{2}{c}{ Total } \\
& $\mathbf{n}$ & $\%$ & $\mathbf{n}$ & $\%$ & $\mathbf{n}$ & $\%$ \\
\hline Envelhecimento AND Idoso & 867 & 38,3 & 00 & 0,0 & 867 & 38,3 \\
\hline Envelhecimento AND Cuidadores. & 65 & 3,0 & 00 & 0,0 & 65 & 3,0 \\
\hline Idoso AND Cuidadores. & 226 & 10,0 & 905 & 40,0 & 1131 & 50,0 \\
\hline Envelhecimento AND Idoso AND Cuidadores & 43 & 1,9 & 154 & 6,8 & 197 & 8,7 \\
\hline Total & 1201 & 53,2 & 1059 & 46,8 & 2260 & 100,0
\end{tabular}

Fonte: BVS, 2020

Tabela 2 - Perfil da amostra do estudo, após aplicação dos critérios de elegibilidade, conforme descritores e bases de dados.

\begin{tabular}{lcccccccccc}
\multicolumn{1}{c}{ Descritores } & \multicolumn{3}{c}{ SCIELO } & \multicolumn{4}{c}{ LILACS } & \multicolumn{3}{c}{ Total } \\
& AS & AE & AU & AS & AE & AU & AS & AE & AU \\
Envelhecimento AND Idoso & 867 & 867 & 00 & 00 & 00 & 00 & 867 & 867 & 00 \\
$\begin{array}{l}\text { Envelhecimento AND } \\
\text { Cuidadores. }\end{array}$ & 65 & 63 & 02 & 00 & 00 & 00 & 65 & 63 & 02 \\
\hline $\begin{array}{l}\text { Idoso AND Cuidadores. } \\
\text { Envelhecimento AND Idoso }\end{array}$ & 226 & 224 & 02 & 905 & 903 & 02 & 1131 & 1127 & 04 \\
AND Cuidadores & 43 & 37 & 06 & 154 & 152 & 02 & 197 & 189 & 08 \\
Total & 1201 & 1191 & 10 & 1059 & 1055 & 04 & 2260 & 2246 & 14
\end{tabular}

Fonte: BVS, 2020. AS = Artigos Selecionados (amostragem), AE = Artigos Excluídos, AU = Artigos Utilizados (amostra). pesquisa por meio desses descritores nas bases de dados supracitados, refinando a busca para o período de 2009 a outubro de 2019; e, 3) procedeu se com a análise critica dos estudos, excluindo aqueles não condizentes com o escopo da pesquisa, bem como as produções duplicadas.

Inicialmente realizou-se a leitura dos títulos e resumos para análise das publicações, de modo que foram adotados os seguintes critérios de inclusão para a composição da amostra: (1) periódicos indexados e publicados em revistas nacionais e internacionais durante o período de 2009 a 2019; (2) artigos de periódicos escritos em língua portuguesa e/ ou apresentem resumo em língua portuguesa; (3) e o artigo ser relacionado ao tema proposto. As publicações que não disponibilizaram o texto completo foram excluídas do estudo. A busca pela amostra do estudo foi realizada no período de setembro a outubro de 2020.

Utilizou-se um formulário de elaboração própria como instrumento de coleta de dados. Este contemplava as seguintes variáveis: título, autor, ano de publicação, objetivo, método e resultados. Os dados do estudo foram armazenados no PRISMA ${ }^{(12)}$, sendo este um software utilizado para revisões sistemáticas e meta-análises, e posteriormente expressos em uma tabela contendo as variáveis descritas anteriormente.

Na SCIELO obtiveram-se 1201 artigos, sendo que, destes, 10 atenderam aos critérios de elegibilidade estabelecidos. Na LILACS obtiveram-se 1059 artigos, sendo que, destes, quatro foram incluídos na amostra por atenderem aos critérios de inclusão da pesquisa. Assim, a amostra final do estudo foi composta por 14 artigos que estavam relacionados à temática, ao objetivo desse estudo e contemplavam os critérios de inclusão estabelecidos conforme evidenciado na Figura 1. Ainda, é demonstrado pela Tabela 1 e pela Tabela 2 , respectivamente, o perfil da amostragem e da amostra após aplicação dos critérios de elegibilidade, conforme descritores e bases de dados. 
Nessa perspectiva, a análise dos estudos encontrados foi sistematizada seguindo as etapas da pesquisa bibliográfica, sendo elas: (1) levantamento bibliográfico preliminar nas bases de dados; (2) leitura exploratória dos estudos, verificando a viabilidade dos artigos encontrados para a revisão literária; (3) leitura seletiva, analisando, de maneira específica, a pertinência dos estudos; (4) leitura analítica, sumarizando as informações encontradas de maneira critica; (5) leitura interpretativa, articulando os conhecimentos versados em todos os estudos analisados; e (6) elaboração do texto final ${ }^{(13)}$.
RESULTADOS

Ao analisar os artigos selecionados, identificou-se que todos versam acerca da importância do cuidador na assistência ao idoso, conforme apresentado no Quadro 1. Estes destacam a necessidade do cuidado destinado aos idosos, os quais, geralmente, encontram-se dependente necessitando de auxílio nas suas necessidades básicas. E buscam entender o cotidiano dos cuidadores de idosos no processo que envolve a assistência ao mesmo. Dentre as temáticas abordadas nos estudos, destacam-se: o cuidador familiar, cuidados em domicilio e as principais implicações para o cuidador familiar. Esses tópicos propor- cionam tecer pilares temáticos de análise dos resultados da pesquisa, os quais serão discutidos posteriormente.

\section{DISCUSSÃO}

Os cuidadores familiares de idosos geralmente são escolhidos observando-se gênero (predominantemente a mulher); proximidade física (quem convive com o idoso) e afetiva (estabelecida pela relação conjugal e entre pais e filhos). Em razão disso, essas pessoas são parentes próximos do idoso, como cônjuge e filhos, quase sempre mulheres, que moram na mesma casa e são aposentados ${ }^{(14,15,16)}$. Cabe destacar que na vida familiar, existe

Quadro 1 - Apresentação da amostra conforme as seguintes variáveis: título, autor, ano de publicação, objetivo, método e resultados.

\begin{tabular}{|c|c|c|c|c|c|c|}
\hline $\mathrm{N}^{\circ}$ & Titulo & Autor & Ano & Objetivo & Método & Resultados \\
\hline 1 & $\begin{array}{l}0 \text { cuidado do idoso } \\
\text { no contexto familiar: } \\
\text { percepção da equipe } \\
\text { de saúde da família }\end{array}$ & $\begin{array}{l}\text { Borges; } \\
\text { Telles(14) }\end{array}$ & 2010 & $\begin{array}{l}\text { Apresentar a experiên- } \\
\text { cia no cuidado domicili- } \\
\text { ário e as dificuldades a } \\
\text { partir da percepção dos } \\
\text { profissionais de saúde } \\
\text { da família. }\end{array}$ & $\begin{array}{l}\text { Pesquisa qualitativa que } \\
\text { utilizou estudo de caso e } \\
\text { análise de conteúdo. }\end{array}$ & $\begin{array}{l}\text { Na experiência da equipe, o cuidado } \\
\text { domiciliar ao idoso dependente é re- } \\
\text { alizado quando o mesmo se encontra } \\
\text { num estágio de comprometimento da } \\
\text { capacidade funcional mais avançado. } \\
\text { Os profissionais apresentaram dificul- } \\
\text { tadores, tais como a demanda aumen- } \\
\text { tada da USF, transporte insuficiente e } \\
\text { equipe incompleta, e ainda se sentem } \\
\text { despreparados para esse cuidado. }\end{array}$ \\
\hline 2 & $\begin{array}{l}\text { A dinâmica da família } \\
\text { de idosos mais idosos } \\
\text { no contexto de Porto, } \\
\text { Portugal }\end{array}$ & $\begin{array}{l}\text { Gonçalves } \\
\text { et al.(15) }\end{array}$ & 2011 & $\begin{array}{l}\text { Conhecer a dinâmica de } \\
\text { família de idosos com } \\
80 \text { anos ou mais, sob } \\
\text { cuidados do familiar } \\
\text { cuidador, em domicílio. }\end{array}$ & $\begin{array}{c}\text { Estudo descritivo, } \\
\text { exploratório, de natureza } \\
\text { diagnóstico-avaliativa, com } \\
\text { abordagem quantitativa. }\end{array}$ & $\begin{array}{l}\text { Aumento de cuidador masculino e de } \\
\text { cônjuge idoso de seu par dependente } \\
\text { e inclusão substancial no elenco de } \\
\text { familiares cuidadores: netos, sobrinhos } \\
\text { e irmãos. Estilo de vida do cuidador } \\
\text { revelou-se regular como também a QV } \\
\text { de ambos: cuidador e idoso, apesar de } \\
\text { a dinâmica de família se mostrar de } \\
\text { boa funcionalidade. }\end{array}$ \\
\hline 3 & $\begin{array}{l}0 \text { dia a dia de cuidado- } \\
\text { res familiares de idosos } \\
\text { dependentes }\end{array}$ & $\begin{array}{l}\text { Scalco et } \\
\text { al.(16) }\end{array}$ & 2013 & $\begin{array}{l}\text { Entender o que é cuidar } \\
\text { de um idoso dependen- } \\
\text { te através do olhar de } \\
\text { seus familiares. }\end{array}$ & $\begin{array}{l}\text { Estudo descritivo-explora- } \\
\text { tório, fenomenológico, com } \\
\text { abordagem qualitativa. }\end{array}$ & $\begin{array}{l}\text { Foi possível compreender que a } \\
\text { vivência de se tornar cuidador familiar } \\
\text { é marcada por etapas bem definidas. } \\
\text { Inicialmente o familiar se depara com } \\
\text { uma situação para qual não está } \\
\text { adequadamente preparado. Após o } \\
\text { primeiro contato com as tarefas do } \\
\text { cuidado, os cuidadores passam a con- } \\
\text { viver e a observar outras dificuldades } \\
\text { que surgem no decorrer da experiên- } \\
\text { cia de cuidar, enquanto se constrói } \\
\text { a nova relação com o idoso agora } \\
\text { dependente. }\end{array}$ \\
\hline
\end{tabular}




\begin{tabular}{|c|c|c|c|c|c|c|}
\hline 4 & $\begin{array}{l}\text { Prevalência e fatores } \\
\text { associados ao cuidado } \\
\text { domiciliar a idosos. }\end{array}$ & $\begin{array}{l}\text { Del Duca; } \\
\text { Thume; } \\
\text { Hallal(17) }\end{array}$ & 2011 & $\begin{array}{l}\text { Estimar a prevalência } \\
\text { do cuidado domiciliar } \\
\text { a idosos e identificar } \\
\text { fatores associados. }\end{array}$ & $\begin{array}{l}\text { Estudo transversal } \\
\text { de base populacional } \\
\text { com abordagem } \\
\text { quantitativa. }\end{array}$ & $\begin{array}{c}\text { A prevalência de cuidado domiciliar foi de } \\
49,5 \% \text { (IC95\%: } 44,5 ; 54,5) \text {. Entre aqueles } \\
\text { que tinham cuidador, } 39,5 \% \text { relataram ser } \\
\text { cuidados pelo cônjuge, enquanto a opção } \\
\text { "cuidador contratado" foi relatada por } \\
4,7 \% \text { dos idosos. Na análise ajustada, ob- } \\
\text { servou-se associação do cuidado domiciliar } \\
\text { com o sexo masculino, ter companheiro, } \\
\text { aumento da idade e presença de incapa- } \\
\text { cidade funcional para AVD. A escolaridade } \\
\text { e o nível de atividade física apresentaram } \\
\text { associação inversa com a ocorrência de } \\
\text { cuidado domiciliar. }\end{array}$ \\
\hline 5 & $\begin{array}{l}\text { Reconhecendo a so- } \\
\text { brecarga e a qualidade } \\
\text { de vida de cuidadores } \\
\text { familiares de idosos } \\
\text { frágeis }\end{array}$ & $\begin{array}{l}\text { Wachholz; } \\
\text { Santos; } \\
\text { Wolf(7) }\end{array}$ & 2013 & $\begin{array}{c}\text { Analisar as correla- } \\
\text { ções entre o grau de } \\
\text { dependência funcional } \\
\text { de idosos residentes na } \\
\text { comunidade, o nível de } \\
\text { sobrecarga relacio- } \\
\text { nada ao cuidado e a } \\
\text { percepção de qualidade } \\
\text { de vida dos cuidado- } \\
\text { res familiares desses } \\
\text { idosos. }\end{array}$ & $\begin{array}{c}\text { Estudo observacional, } \\
\text { descritivo e analítico, } \\
\text { com amostragem não } \\
\text { probabilística selecio- } \\
\text { nada por conveni- } \\
\text { ência e abordagem } \\
\text { quantitativa. }\end{array}$ & $\begin{array}{l}\text { Foram entrevistados } 45 \text { cuidadores, } \\
\text { predominando mulheres }(91,11 \%) \text { com } \\
\text { elevada escolaridade, assistindo idosos } \\
\text { funcionalmente dependentes }(66,77 \%) \text {. } \\
\text { Percebeu-se sobrecarga moderada e/ou } \\
\text { severa em } 75,55 \% \text { da amostra. Observou-se } \\
\text { correlação entre dependência funcional e } \\
\text { maior sobrecarga no cuidador }(r=-0,281, p \\
=0,013) \text { e pior percepção de qualidade de } \\
\text { vida. A regressão linear múltipla identificou } \\
\text { forte associação entre sobrecarga relaciona- } \\
\text { da ao cuidado e o domínio psicológico do } \\
\text { WHOQOL-bref e o tempo como cuidador. }\end{array}$ \\
\hline 6 & $\begin{array}{l}\text { Saúde do cuidadores } \\
\text { de idosos: um desafio } \\
\text { para o cuidador }\end{array}$ & $\begin{array}{l}\text { Mendes; } \\
\text { Miranda; } \\
\text { Bor- } \\
\text { ges(18) }\end{array}$ & 2011 & $\begin{array}{l}\text { Refletir sobre a saúde } \\
\text { do cuidador de idosos } \\
\text { dependentes que } \\
\text { negligenciam sua vida } \\
\text { em prol do cuidado. }\end{array}$ & $\begin{array}{c}\text { Estudo bibliográfico, } \\
\text { descritivo, retrospec- } \\
\text { tivo. }\end{array}$ & $\begin{array}{l}\text { O perfil de cuidadores apresentados é } \\
\text { maioria mulheres, com baixa instrução e } \\
\text { que acumulam outras atividades além de } \\
\text { cuidar de idosos, e estão sujeitas a sofrer } \\
\text { sobrecarga e algumas patologias. Relata-se } \\
\text { que o cuidado domiciliar proporciona à } \\
\text { família ficar mais próxima do idoso, além } \\
\text { de evitar infecção hospitalar. Porém, várias } \\
\text { mudanças ocorrem na vida dos familiares e } \\
\text { cuidadores. }\end{array}$ \\
\hline 7 & $\begin{array}{l}\text { Estudos nacionais } \\
\text { sobre cuidadores } \\
\text { familiares de idosos: } \\
\text { revisão integrativa }\end{array}$ & $\begin{array}{l}\text { Oliveira; } \\
\text { D'El- } \\
\text { boux(19) }\end{array}$ & 2012 & $\begin{array}{l}\text { Evidenciar o perfil dos } \\
\text { trabalhos publicados } \\
\text { em âmbito nacional e } \\
\text { internacional }\end{array}$ & RIL & $\begin{array}{l}\text { Os autores encontraram grandes índices de } \\
\text { sobrecarga, piora significativa da qualidade } \\
\text { de vida do cuidador, falta de apoio aos cui- } \\
\text { dadores, falta de informação e preparo para } \\
\text { o cuidado, bem como falta de instrumentali- } \\
\text { zação e estudos dentro desta temática. }\end{array}$ \\
\hline 8 & $\begin{array}{l}\text { A importância do } \\
\text { cuidador de idosos na } \\
\text { assistência ao idoso. }\end{array}$ & $\begin{array}{l}\text { Scarpellini } \\
\text { et al.(20) }\end{array}$ & 2011 & $\begin{array}{l}\text { Analisar a produção } \\
\text { científica nacional nos } \\
\text { últimos cinco anos, } \\
\text { acerca do cuidado pres- } \\
\text { tado pelos cuidadores } \\
\text { na assistência ao idoso. }\end{array}$ & RIL & $\begin{array}{l}\text { Inúmeras alterações ocorrem decorrentes do } \\
\text { processo de envelhecimento fazendo que } \\
\text { o idoso necessite de alguém para auxiliá-lo } \\
\text { em atividades do cotidiano. E, o cuidador, } \\
\text { necessita desenvolver características como } \\
\text { habilidade, sensibilidade e empatia, bem } \\
\text { como ser capacitado para que entenda } \\
\text { o idoso para além da patologia que o } \\
\text { acomete. Assim, a enfermagem necessita } \\
\text { instrumentalizar e dar suporte, aos cuidado- } \\
\text { res, para que desempenham o cuidado com } \\
\text { qualidade. }\end{array}$ \\
\hline
\end{tabular}




\begin{tabular}{|c|c|c|c|c|c|c|}
\hline 9 & $\begin{array}{l}0 \text { processo do cuidar } \\
\text { de idosos hospitali- } \\
\text { zados: percepção dos } \\
\text { acompanhantes de um } \\
\text { hospital universitário }\end{array}$ & $\begin{array}{l}\text { Silva et al. } \\
\text { (21) }\end{array}$ & 2017 & $\begin{array}{l}\text { Identificar a percepção, } \\
\text { quanto ao processo de } \\
\text { cuidar, de acompanhan- } \\
\text { tes de idosos de um } \\
\text { hospital universitário, } \\
\text { muitas vezes seus } \\
\text { cuidadores pós-hospi- } \\
\text { talização, no ambiente } \\
\text { domiciliar. }\end{array}$ & $\begin{array}{c}\text { Estudo descritivo, } \\
\text { exploratório, transver- } \\
\text { sal, com abordagem } \\
\text { qualitativa. }\end{array}$ & $\begin{array}{l}\text { Os entrevistados revelaram, por meio de } \\
\text { suas respostas, a importância de sua presen- } \\
\text { ça, como acompanhantes, principalmente } \\
\text { quando são membros da família do idoso. } \\
\text { A presença de um acompanhante, junto } \\
\text { ao idoso hospitalizado, proporciona-lhe } \\
\text { amparo biopsicoemocional, o que contribui } \\
\text { para a sua recuperação. Quando este não } \\
\text { dispõe de companhia, esta forçada solidão } \\
\text { pode lhe ocasionar degeneração psíquica e } \\
\text { em longo prazo fazê-lo vivenciar distúrbios } \\
\text { depressivos. }\end{array}$ \\
\hline 10 & $\begin{array}{l}\text { Fatores associados } \\
\text { à qualidade de vida } \\
\text { de cuidadores de } \\
\text { idosos em assistência } \\
\text { domiciliária }\end{array}$ & $\begin{array}{c}\text { Ferreira; } \\
\text { Alexandre; } \\
\text { Lemos(8) }\end{array}$ & 2011 & $\begin{array}{l}\text { Investigar se o com- } \\
\text { portamento da QV de } \\
\text { cuidadores de idosos } \\
\text { em assistência domicili- } \\
\text { ária pode ser influen- } \\
\text { ciado por características } \\
\text { sociodemográficas, pela } \\
\text { rede de suporte ofere- } \\
\text { cida ao cuidador e por } \\
\text { variáveis relacionadas } \\
\text { ao ato de cuidar. }\end{array}$ & $\begin{array}{l}\text { Estudo descritivo, ex- } \\
\text { ploratório, de natureza } \\
\text { seccional, com abor- } \\
\text { dagem quantitativa. }\end{array}$ & $\begin{array}{l}\text { A análise de regressão linear mostrou rela- } \\
\text { ção independente entre três domínios do } \\
\text { SF-36 e o maior número de horas dedicadas } \\
\text { ao cuidado: domínios capacidade funcional, } \\
\text { aspecto fisico e aspecto emocional. Possuir } \\
\text { mais de oito anos de escolaridade implicou } \\
\text { em melhor pontuação no domínio estado } \\
\text { geral de saúde e pior pontuação no domínio } \\
\text { aspecto social. Os cuidadores com mais } \\
\text { de } 60 \text { anos de idade apresentaram pior } \\
\text { pontuação no domínio aspecto físico e as } \\
\text { mulheres pior pontuação no domínio dor. Os } \\
\text { filhos ou cônjuges que prestam cuidado aos } \\
\text { seus pais ou parceiros apresentaram pior } \\
\text { pontuação no domínio aspecto emocional. } \\
\text { Os cuidadores que modificaram sua rotina } \\
\text { para prestar os cuidados apresentaram pior } \\
\text { pontuação no domínio saúde mental. }\end{array}$ \\
\hline 11 & $\begin{array}{c}\text { Cuidado realizado pelo } \\
\text { cuidador familiar ao } \\
\text { idoso dependente, em } \\
\text { domicilio, no contexto } \\
\text { da estratégia de saúde } \\
\text { da família. }\end{array}$ & $\begin{array}{l}\text { Almeida } \\
\text { et al.(22) }\end{array}$ & 2012 & $\begin{array}{l}\text { Descrever a maneira } \\
\text { como os cuidadores } \\
\text { familiares realizam o } \\
\text { cuidado aos idosos em } \\
\text { condição de depen- } \\
\text { dência. }\end{array}$ & $\begin{array}{l}\text { Estudo exploratório- } \\
\text {-descritivo de aborda- } \\
\text { gem qualitativa. }\end{array}$ & $\begin{array}{l}\text { Os resultados apontaram que o cuidado } \\
\text { desenvolvido ao idoso em condição de } \\
\text { dependência é uma atividade que leva a } \\
\text { mudanças na vida dos cuidadores, o que } \\
\text { pode gerar estressores de ordem física, emo- } \\
\text { cional e social. }\end{array}$ \\
\hline 12 & $\begin{array}{l}\text { Determinantes da } \\
\text { tensão do cuidador } \\
\text { familiar de idosos } \\
\text { dependentes. }\end{array}$ & $\begin{array}{c}\text { Fernan- } \\
\text { des; } \\
\text { Garcia(23) }\end{array}$ & 2009 & $\begin{array}{l}\text { Investigar os determi- } \\
\text { nantes da tensão do } \\
\text { cuidador familiar de } \\
\text { idosos dependentes. }\end{array}$ & $\begin{array}{l}\text { Estudo descritivo, } \\
\text { exploratório, com } \\
\text { abordagem qualita- } \\
\text { tiva. }\end{array}$ & $\begin{array}{l}\text { Os resultados apontam que o fenômeno } \\
\text { investigado se origina a partir de determi- } \\
\text { nantes relacionados ao cuidador, aos déficits } \\
\text { do idoso, à interação idoso/cuidador, ao } \\
\text { ambiente, e às demandas de cuidado. }\end{array}$ \\
\hline 13 & $\begin{array}{l}\text { Serviços de atenção ao } \\
\text { idoso e estratégias de } \\
\text { cuidado domiciliar e } \\
\text { institucionais }\end{array}$ & $\begin{array}{l}\text { Ferreira; } \\
\text { Bansi; Pas- } \\
\text { choal(4) }\end{array}$ & 2014 & $\begin{array}{c}\text { Descrever e comparar } \\
\text { os serviços assistência } \\
\text { domiciliar, Programa } \\
\text { Acompanhante de } \\
\text { Idosos e instituições } \\
\text { de longa permanência } \\
\text { para idosos quanto às } \\
\text { possíveis diferenças e } \\
\text { semelhanças, demanda } \\
\text { dos usuários, fluxo } \\
\text { assistencial e gestão de } \\
\text { serviços. }\end{array}$ & RIL & $\begin{array}{l}\text { No total, } 32 \text { estudos foram incluídos na revi- } \\
\text { são. Observou-se que a população atendida } \\
\text { é predominantemente do sexo feminino, } \\
\text { com idade avançada, e recebe assistência } \\
\text { multiprofissional. Os serviços de assistência } \\
\text { domiciliar e o Programa Acompanhante de } \\
\text { Idosos valorizam a manutenção da família e } \\
\text { da comunidade como ambiente terapêu- } \\
\text { tico, postergando a institucionalização. A } \\
\text { presença do cuidador mostrou-se como } \\
\text { um dos fatores de maior influência para a } \\
\text { permanência dos cuidados domiciliares. }\end{array}$ \\
\hline
\end{tabular}




\begin{tabular}{|c|c|c|c|c|c|c|}
\hline 14 & $\begin{array}{c}\text { Convívio e cuidado } \\
\text { familiar na quarta } \\
\text { idade: qualidade de } \\
\text { vida de idosos e seus } \\
\text { cuidadores. }\end{array}$ & $\begin{array}{l}\text { Gonçalves } \\
\text { et al.(24) }\end{array}$ & 2013 & $\begin{array}{l}\text { Avaliar a dinâmica da } \\
\text { família, a qualidade e o } \\
\text { estilo de vida de idosos } \\
\text { da quarta idade e de seus } \\
\text { familiares cuidadores. } \\
\text { Método: Estudo descritivo } \\
\text { do qual participaram } 100 \\
\text { idosos e seus cuidadores. }\end{array}$ & $\begin{array}{l}\text { Estudo descritivo, explo- } \\
\text { ratório, transversal, com } \\
\text { abordagem quantitativa. }\end{array}$ & $\begin{array}{l}\text { A amostra de idosos caracterizou- } \\
\text {-se por ser a maioria mulher, com } \\
\text { idade média de } 84 \text { anos, portadora } \\
\text { de hipertensão arterial e cardiopatias. } \\
\text { Os cuidadores (67\%) viviam na casa } \\
\text { dos próprios idosos, eram predomi- } \\
\text { nantemente mulheres, entre filhas e } \\
\text { netas, sendo } 20 \% \text { idosos cônjuges de } \\
\text { ambos os sexos. Embora os cuidadores } \\
\text { tenham referido boa saúde e qualidade } \\
\text { de vida, seu estilo de vida atingiu nível } \\
\text { regular. Na ótica dos idosos, a família } \\
\text { apresenta alta disfuncionalidade, em- } \\
\text { bora tenham uma melhor qualidade de } \\
\text { vida em alquns domínios e facetas. }\end{array}$ \\
\hline
\end{tabular}

uma hierarquia de compromisso em relação ao cuidado: em primeiro lugar, vem a esposa e, em seguida, e filhas solteiras ou que vivem sozinhas. Raramente o cuidador é outro parente, uma pessoa jovem, ou um homem ${ }^{(22,23)}$.

Podem-se imaginar ônus desta árdua e desgastante tarefa, forjada numa repetitiva rotina diária incessante, muitas vezes durante anos, com sobrecarga de atividade no seu cotidiano, sendo quase sempre uma atividade solitária e sem descanso, que pode levar o cuidador a um isolamento afetivo e social. Tratando não só de uma sobrecarga nas atividades, mais também de uma ameaça a sua saúde, já que muitos adoecem ou agravam problemas de saúde já existentes. Sabe-se, também, que o cuidador enfrenta rupturas de vínculos, tem sua saúde deteriorada, não tem férias e tem baixa participação social(18,24).

Ser cuidador demanda tempo, espaço, energia, dinheiro, trabalho, paciência, carinho, esforço e boa vontade. As graduais perdas cognitivas, mudanças comportamentais, emocionais e ate de personalidades do idoso exigem uma grande capacidade de adaptação para um convívio. Alguns problemas de saúde que podem acometer os cuidadores são: dores lombares (lombalgias), dores
60

\section{Ser cuidador} demanda tempo, espaço, energia, dinheiro, trabalho, paciência, carinho, esforço e boa vontade. As graduais perdas cognitivas, mudanças comportamentais, emocionais e ate de personalidades do idoso exigem uma grande capacidade de adaptação para um convívio. articulares (artralgias e artrites), hipertensão arterial sistêmica (HAS) - problemas físicos, perda de equilíbrio financeiro e de relacionamento familiar e ocupacionais - sobrecarga objetiva, bem como sintomas psiquiátricos, uso de medicamentos psicotrópicos, efeitos sociais e emocionais - sobrecarga subjetiva ${ }^{(19,21)}$. A alta porcentagem de problemas de coluna parece estar intimamente relacionada com as atividades diárias de cuidados com os idosos, que envolvem o uso da força muscular e, muitas vezes, posturas inadequadas ${ }^{(20)}$.

Com frequência, os cuidadores também são afetados pelas experiências emocionais e psicológicas de sofrimento por que passam as pessoas que são por eles cuidados, e os efeitos dessas inter-relações na qualidade de vida dos cuidadores ainda são apenas parcialmente compreendidos $^{(4,7,15)}$.

As tarefas atribuídas ao cuidador familiar agregam forte impacto em sua vida, pois muitas vezes são executadas sem orientação adequada, sem o suporte dos outros membros da família, e frequentemente alteram toda a rotina de vida anterior, ocupando a maior parte do dia. Por vezes, o familiar que desempenha o papel de cuidador pode acabar adoecendo em decorrência dessa função, 
ao acumular para si atividades relacionadas ao cuidado e as de sua própria rotina pessoal ${ }^{(17)}$.

\section{CONSIDERAÇÕES FINAIS}

Os artigos estudados permitiram identificar aspectos que envolvem o cuidador de idosos e evidencia-se que o cuidador familiar é a pessoa da família que presta cuidado a alguém e é nominado de cuidador informal, assumindo a responsabilidade de cuidar dos outros com ou sem remuneração. A atenção do cuidador familiar de idosos dependentes resulta de fatores biopsicossociais, econômicos e histórico-culturais, nesse sentido, muitas vezes a atitude de cuidar de um idoso com limitações pode impor ao cuidador sobrecarga e conflitos, sendo possível identificar que eles estão sujeitos a complicações osteomusculares, tais como dores lombares e artrites, bem como doenças psíquicas, cardiovasculares (HAS), isolamento social entre outros males. Assim, a saúde física e mental do cuidador é tão importante quanto à do ser cuidado. Ainda, a assistência do cuidador familiar requer direcionamento do olhar, fazendo necessário que os profissionais de saúde ofereçam aos cuidadores, orientações necessárias ao cuidado, promovendo ações sistematizadas, organizadas e metodologicamente apropriadas, como intuito de prevenir agravos a saúde do cuidador, considerando que a atividade de cuidar de um idoso dependente é desgastante e implicam em riscos a saúde física e mental do cuidador 2

\section{Referências}

1. Schimidt TCG, Silva MJP. Percepção e compreensão de profissionais de saúde e estudantes de graduação sobre o envelhecimento e os idosos. Rev. Esc. Enferm. USP [Internet]. 2012 [cited 2021 Feb 6];46(3):612-7. doi: http://doi.org/10.1590/ S0080-62342012000300012

2. Organização Mundial de Saúde. Os usos da epidemiologia no estudo dos idosos. Genebra: OMS, 1984.

3. Brasil. Ministério da Saúde. Lei $n^{\circ} 10.741$, de $1^{\circ}$ de outubro de 2003. Dispõe sobre o Estatuto do Idoso e dá outras providências. Brasília: MS, 2003 [cited 2021 Feb 1]. Disponivel em: http://www.planalto.gov.br/ccivil_03/leis/2003/ 110.741.htm

4. Ferreira FPC, Bansi LO, Paschoal SMP. Serviços de atenção ao idoso e estratégias de cuidado domiciliares e institucionais. Rev. Bras. Geriatr. Gerontol. [Internet]. 2014 [cited 2021 Feb 2];17(4):911-26. doi: http://www.doi. org/10.1590/1809-9823.2014.13053

5. Araújo MOPH, Ceolim MF. Avaliação do grau de independência de idosos residentes em instituições de longa permanência. Rev. Esc. Enferm. USP [Internet]. 2007 [cited 2021 Feb 6];41(3):378-85. doi: http://doi.org/10.1590/5008062342007000300006

6. Marinho LM, Vieira MA, Costa SM, Andrade JMO. Grau de dependência de idosos residentes em instituições de longa permanência. Rev. Gaúcha Enferm. [Internet]. 2013 [cited 2021 Feb 6];34(1):104-10. doi: http://doi.org/10.1590/ S1983-14472013000100013

7. Wachholz PA, Santos RCC, Wolf LSP. Reconhecendo a sobrecarga e a qualidade de vida de cuidadores familiares de idosos frágeis. Rev. Bras. Geriatr. Gerontol. [Internet]. 2013 [cited 2021 Feb 6];16(3):513-26. doi: http://dx.doi.org/10.1590/ S1809-98232013000300010

8. Ferreira CG, Alexandre TS, Lemos ND. Fatores associados à qualidade de vida de cuidadores de idosos em assistência domiciliária. Saúde Soc. [Internet]. 2011 [cited 2021 Feb 6];20(2):398-409. doi: http://doi.org/10.1590/5010412902011000200012

9. Boff L. Saber cuidar: ética do humano - compaixão pela terra. Petrópolis: Vozes, 1999.

10. Vaingankar JA, Subramaniam M, Abdin E, He VY, Chong SA. "How much can I take?": predictors of perceived burden for relatives of people with chronic illness. Ann. Acad. Med. Singap. [Internet]. 2012 [cited 2021 Feb 6];41(5):212-20. Available from: https://www.annals.edu.sg/pdf/41VolNo5May2012/v41N5p212. pdf

11. Gratao ACM, Vendrúscolo TRP, Talmelli LFS, Figueiredo LC, Santos JLF, Rodrigues RAP. Sobrecarga e desconforto emocional em cuidadores de idosos. Texto Contexto - Enferm. [Internet]. 2012 [cited 2021 Feb 6];21(2):304-12. doi: http://doi.org/10.1590/S0104-07072012000200007

12. Galvão TF, Pansani TSA, Harrad D. Principais itens para relatar revisões sistemáticas e meta-análises: a recomendação PRISMA. Epidemiol. Serv. Saúde [Internet]. 2015 [cited 2021 Feb 7];24(2):335-42. doi: https://doi.org/10.5123/
S1679-49742015000200017

13. Gil AC. Métodos e técnicas de pesquisa social. 5. ed. São Paulo: Atlas, 2007. 14. Borges MMMC, Telles JL. 0 cuidado do idoso no contexto familiar: percepção da equipe de saúde da família. Rev. Bras. Geriatr. Gerontol. [Internet]. 2010 [cited 2021 Feb 7];13(3):349-60. doi: https://doi.org/10.1590/S180998232010000300002

15. Gonçalves LHT, Costa MAM, Martins MM, Nassar SM, Zunino R. A dinâmica da família de idosos mais idosos no contexto de Porto, Portugal. Rev. Latino-Am. Enferm. [Internet]. 2011 [cited 2021 Feb 7];19(3):458-66. doi: http://dx.doi org/10.1590/50104-11692011000300003

16. Scalco JC, Tavares KO, Vieira L, Silva JR, Bastos CCCB. 0 dia a dia de cuidadores familiares de idosos dependentes. Rev. Kairós Gerontol. [Internet]. 2013 [cited 2020 Sept 20];2(16):191-208. doi: https://doi.org/10.23925/2176901X.2013v16i1p191-208

17. Del Duca GF, Thumé E, Hallal PC. Prevalência e fatores associados ao cuidado domiciliar a idosos. Rev. Saúde Pública [Internet]. 2011 [cited 2020 Dez 7];45(1):113-20. doi: https://doi.org/10.1590/\$0034-89102010005000047

18. Mendes GD, Miranda SM, Borges MMMC. Saúde do cuidador de idosos: um desafio para o cuidado. Rev. Enferm. Integr. [Internet]. 2011 [cited 2020 Dez 7];3(1):408-21. Available from: http://estacio.webaula.com.br/BiBlioTECA/Acervo/Complementar/Complementar_21605.pdf

19. Oliveira DC, D'Elboux MJ. Estudos nacionais sobre cuidadores familiares de idosos: revisão integrativa. Rev. Bras. Enferm. [Internet]. 2012 [cited 2021 Feb 7];65(5):829-38. doi: https://doi.org/10.1590/\$0034-71672012000500017 20. Scarpellini M, Loro MM, Kolankiewicz ACB, Rosanelli CLP, Gomes JS, Zeitoune RCG. A importância do cuidador de idosos na assistência ao idoso. Rev. Contexto Saúde [Internet]. 2011 [cited 2020 Nov 23];10(20):85-92. doi: https://doi. org/10.21527/2176-7114.2011.20.85-92

21. Silva PLN, Alves ECS, Veloso NEB, Gamba MA, Teles MAB, Oliveira KCF. 0 processo do cuidar de idosos hospitalizados: percepção dos acompanhantes de um hospital universitário. Rev. Kairós Gerontol. [Internet]. 2017 [cited 2021 Feb 7];20(esp):175-90. doi: https://doi.org/10.23925/2176-901X.2017v20iEspecial23p175-190

22. Almeida L, Azevedo RCS, Reiners AAO, Sudré MRS. Cuidado realizado pelo cuidador familiar ao idoso dependente, em domićlio, no contexto da estratégia de Saúde da Família. Texto Contexto - Enferm. [Internet]. 2012 [cited 2021 Feb 7];21(3):543-8. doi: https://doi.org/10.1590/S0104-07072012000300008

23. Fernandes MGM, Garcia TR. Determinantes da tensão do cuidador familiar de idosos dependentes. Rev. Bras. Enferm. [Internet]. 2009 [cited 2021 Feb 7];62(1):57-63. doi: https://doi.org/10.1590/50034-71672009000100009 24. Gonçalves LTH, Leite MT, Hildebrandt LM, Bisogno SC, Biasuz S, Falcade BL. Convívio e cuidado familiar na quarta idade: qualidade de vida de idosos e seus cuidadores. Rev. Bras. Geriatr. Gerontol. [Internet]. 2013 [cited 2021 Feb 7];16(2):315-25. doi: http://dx.doi.org/10.1590/S1809-98232013000200011 